\title{
Spectrum of clinical characteristics of chronic suppurative otitis media unsafe type: a retrospective study from a tertiary care teaching hospital in Central India
}

\author{
Rashmi Hansdah $^{1 *}$, Kavita Sachdeva ${ }^{2}$
}

Department of Otolaryngology and Head and Neck Surgery, ${ }^{1}$ JIPMER, Puducherry, India ${ }^{2}$ NSCB Medical College, Jabalpur, India

Received: 05 June 2021

Revised: 19 June 2021

Accepted: 21 June 2021

\section{*Correspondence:}

Dr. Rashmi Hansdah,

E-mail: dr.rashmi.hansdah@gmail.com

Copyright: () the author(s), publisher and licensee Medip Academy. This is an open-access article distributed under the terms of the Creative Commons Attribution Non-Commercial License, which permits unrestricted non-commercial use, distribution, and reproduction in any medium, provided the original work is properly cited.

\section{ABSTRACT}

Background: Chronic suppurative otitis media (CSOM)-unsafe type or atticoantral disease or chronic otitis mediasquamosal type is a commonly encountered bone eroding disease of the middle ear whose complications can be potentially fatal.

Methods: Retrospective analysis of 80 patients who underwent mastoid exploration in the department of otolaryngology and head and neck surgery, NSCBMCH, Jabalpur between June 2016 and May 2017.

Results: Unsafe CSOM is commoner in young males of 16-30-year age group. Foul smelling, scanty, purulent ear discharge was the commonest symptom $(97.5 \%)$. Attic perforation was the most consistent otoscopic finding $(47.5 \%$ cases). $15 \%$ of our patients had central perforations. Conductive hearing loss was most common (62\%) followed by mixed hearing loss $(23 \%)$ and sensorineural hearing loss $(11 \%)$. Commonest complication encountered was mastoiditis (27 cases). Mastoidectomy with tympanoplasty was done in almost all cases (97.5\%). Attic (96.2\%), additus $(90 \%)$, and antrum $(86.2 \%)$ were commonly involved by disease process. Incus was found to be most susceptible to erosion $(88.5 \%)$ while stapes was most resistant $(36.25 \%)$.

Conclusions: Unsafe CSOM presenting late warrant prompt diagnosis and surgical intervention. Unusual presentation like retropharyngeal abscess and trismus should raise suspicion of complicated unsafe CSOM in patients with history of otorrhoea. Canal wall down mastoidectomy with rehabilitation of hearing is the surgery of choice in patients who are unlikely to follow up regularly.

Keywords: Unsafe CSOM, Atticoantral disease, Chronic otitis media squamosal type, Retropharyngeal abscess, Mastoidectomy

\section{INTRODUCTION}

CSOM-unsafe type or atticoantral disease or chronic otitis media-squamosal type is characterised by bone eroding disease, either cholesteatoma or granulations. The diseased ear is deemed 'unsafe' because of the dangers of life-threatening complications arising due to bone erosion. ${ }^{1}$ The patients with unsafe ear are usually ignorant about the disease, seeking advice for blood- stained ear discharge, hearing loss or complications. The complex anatomy of temporal bone and its anatomical variations make certain ears are more prone to unsafe type of ear disease and its consequences. With increasing awareness of the disease, availability of ENT surgeons, unsafe disease entity with complications have decreased. However, it still contributes a significant load of patients.

These patients with bone eroding disease should undergo thorough evaluation before being subjected to mastoid 
exploration. The type of surgery usually depends upon the hearing status and per op extent of destruction by disease. $X$ ray of the mastoids is not a very sensitive investigation. It is good initial imaging tool for identifying a sclerosed, contracted mastoid, low lying dura or anteriorly placed sigmoid sinus. High resolution computed tomography scan (CT scan) of the temporal bone has revolutionised the pre-operative assessment of disease by picking up the anatomical variations in the temporal bone, the extent of disease, erosion of ossicles, erosion of dura, facial canal, etc. thereby allowing better pre-operative planning of surgery.

This retrospective study was undertaken with objective to study the clinical characteristics of unsafe CSOM. The clinical features and intraoperative findings of the patients in study group were documented and analysed.

\section{METHODS}

The study was undertaken after obtaining approval from the institute ethics committee. Convenience sampling method was used. Retrospective analysis of 80 cases of unsafe ear operated over a period of 1 year (June 2016 to May 2017) in the department of ENT, Netaji Subhash Chandra Bose medical college hospital, Jabalpur, Madhya Pradesh was done. The patient's clinical files were accessed to acquire the required data. The patients' clinical profile was accessed, demography, presentation, audiometric evaluation and temporal bone imaging were done preoperatively. Other preoperative investigations included complete hemogram, renal function test, liver function test, serology, chest x ray, and ECG.

All patients underwent mastoid exploration. The extent of the disease was noted with respect to the origin and path taken by the disease consequently leading to erosion of ossicles and intracranial complications if any. Surgeries were done under local anaesthesia/general anaesthesia by post auricular approach. As ours is a teaching hospital, post-graduate residents performed initial steps of surgery. Pre, per and post-op complications were noted down. After bone work, depending on the extent of disease, hearing status, temporalis fascia graft was kept over the ossicle or residual middle ear cavity. Cartilage was used in some cases. Post-auricular wound was closed in 2 layers. Pack removal was done on $5^{\text {th }}$ post-operative day in cases of mastoidectomy with tympanoplasty while suture removal was done on the $7^{\text {th }}$ post-ope day. Gelfom was usually left undisturbed till 1 month. All received intravenous antibiotics and nasal decongestant drops. Patients were followed up on $7^{\text {th }}, 21^{\text {st }}$ day and 1.5 months. SPSS software was used to statistically analyse data.

\section{RESULTS}

Age of patients in this study ranged from 5 years to 60 years. Most commonly the disease was seen in 16-30year age group (47.5\%). Paediatric patients (up to 15 years) constituted 23 cases $(28.7 \%)$. Disease was least common in the 46-60-year age group (5\%) (Table 1).

Table 1: Age distribution of the study group.

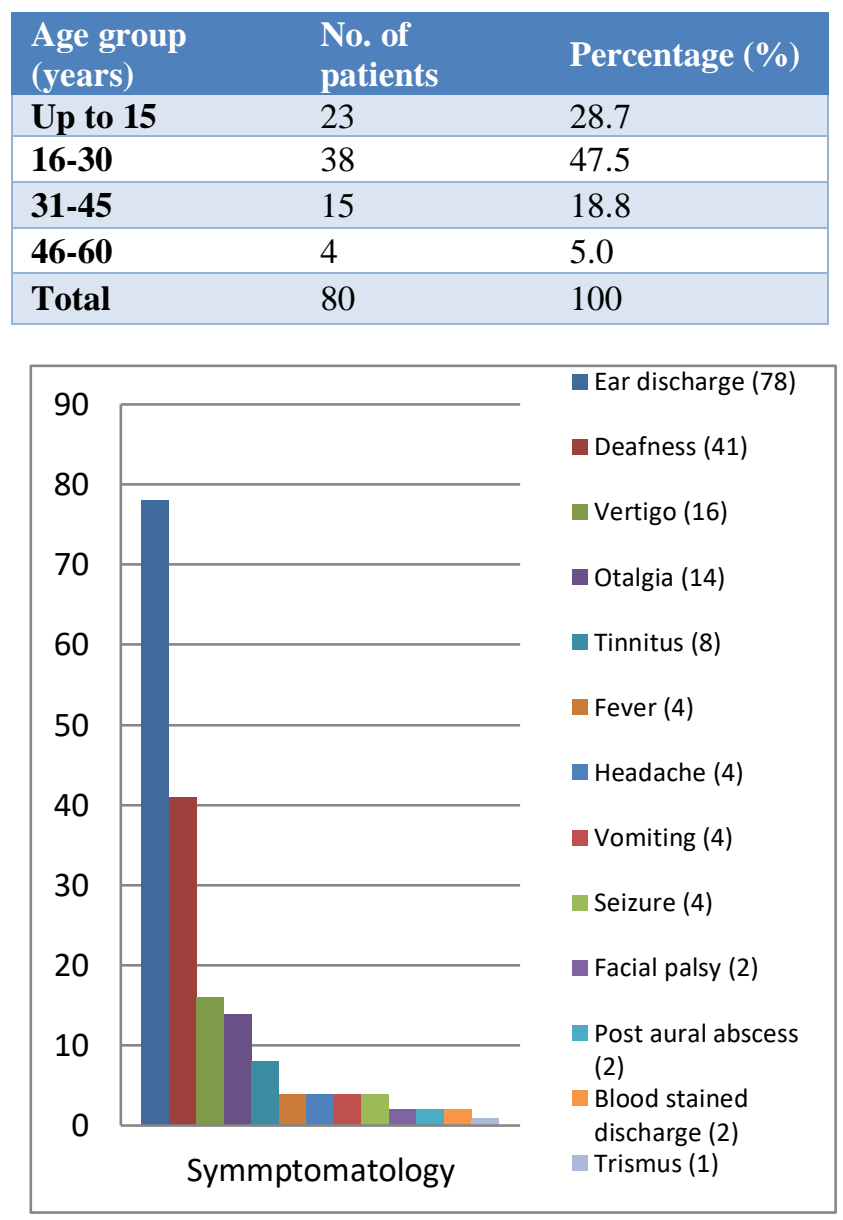

Figure 1: Symptomatology.

Ear discharge $(97.5 \%)$ was the commonest symptom followed by hearing loss $(57.2 \%)$ and vertigo $(20 \%)$. Trismus was a rare symptom seen in a single patient in this series.

Table 2: Otoscopic examination findings.

\begin{tabular}{|c|c|c|c|c|c|}
\hline \multirow{2}{*}{\multicolumn{2}{|c|}{$\begin{array}{l}\text { Otoscopic finding } \\
\text { Cholesteatoma }\end{array}$}} & \multirow{2}{*}{$\begin{array}{l}\text { No. of } \\
\text { cases } \\
45\end{array}$} & & \multicolumn{2}{|c|}{$\begin{array}{l}\text { Percentage } \\
(\%)\end{array}$} \\
\hline & & & & 56.2 & 56.2 \\
\hline \multirow{4}{*}{$\begin{array}{l}\text { Tympanic } \\
\text { membrane } \\
\text { perforation }\end{array}$} & Attic & 38 & \multirow{4}{*}{54} & 47.5 & \multirow{4}{*}{67.5} \\
\hline & Central & 12 & & 15.0 & \\
\hline & Marginal & 2 & & 2.5 & \\
\hline & Multiple & 2 & & 2.5 & \\
\hline \multirow{2}{*}{$\begin{array}{l}\text { Retraction } \\
\text { pocket }\end{array}$} & PSRP & 20 & & 25.0 & \multirow{2}{*}{32.5} \\
\hline & ASRP & 6 & 26 & 7.5 & \\
\hline \multicolumn{2}{|c|}{$\begin{array}{l}\text { Posterior canal wall } \\
\text { sagging }\end{array}$} & 13 & & 16.3 & 16.3 \\
\hline \multicolumn{2}{|l|}{ Aural polyp } & 8 & & 10 & 10 \\
\hline \multicolumn{2}{|c|}{ Sagging roof of EAC } & 2 & & 2.5 & 2.5 \\
\hline
\end{tabular}


Frank cholesteatoma was the most consistent otoscopic finding (45 cases), followed by tympanic membrane perforation (54 cases) and retraction pocket (26 cases)

Among retraction pockets, postero-superior retraction pocket (PSRP; 20 cases) was $>3$ times commoner than anterio-superior retraction pockets (ASRP; 6 cases). Interestingly, 12 cases had central perforation.

Mastoiditis was the commonest complication preoperatively (27 cases) and the rarest was retropharyngeal abscess, in one case. Other complications encountered were labyrinthitis, post aural abscess, brain abscess, lateral sinus thrombophlebitis and facial palsy.

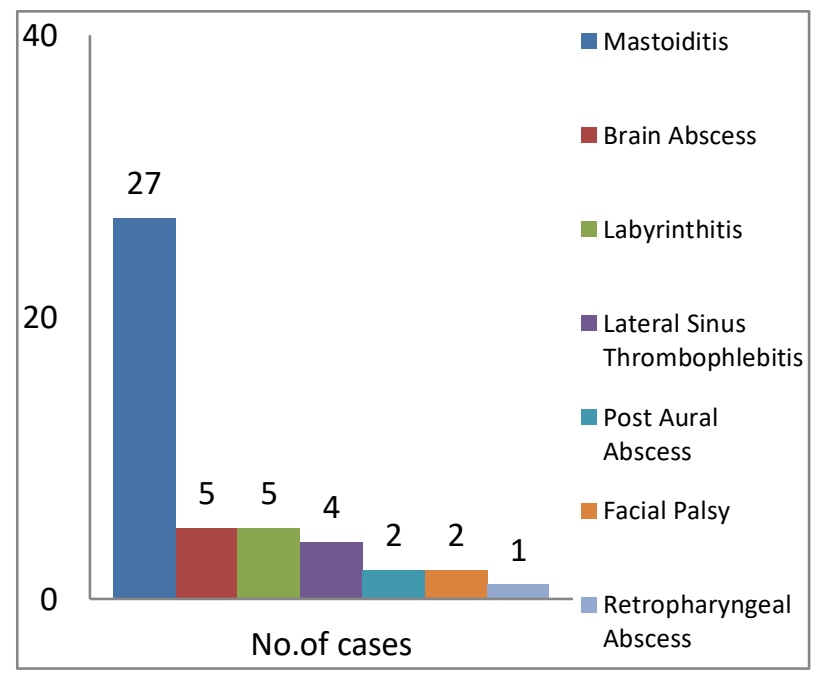

Figure 3: Pre-operative complications.

Conductive hearing loss was the commonest (>60\%) type of hearing loss. Also, $4 \%$ of the patients in the series had absolutely normal hearing.

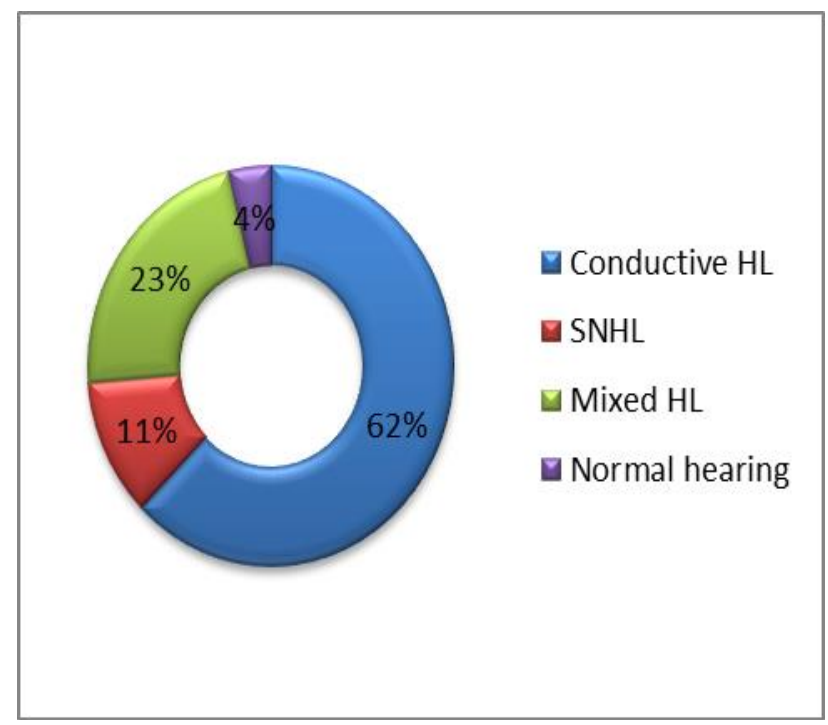

*HL-Hearing loss; SNHL-Sensory neural hearing loss.

Figure 3: Pure tone audiometry.
All the 80 mastoids showed sclerosis on $\mathrm{X}$ ray mastoid Schuller's view. Secondary sclerosis was seen in $57.8 \%$ cases while $42.2 \%$ cases showed primary sclerosis.

Table 3: Surgery performed.

\begin{tabular}{|lll|}
\hline Surgery & No. of cases & $\begin{array}{l}\text { Percentage } \\
(\%)\end{array}$ \\
\hline $\begin{array}{l}\text { Modified radical } \\
\text { mastoidectomy }+ \\
\text { tympanoplasty }\end{array}$ & 78 & 97.4 \\
\hline $\begin{array}{l}\text { Atticoantrostomy + } \\
\text { type III tympanoplasty }\end{array}$ & 1 & 1.3 \\
\hline $\begin{array}{l}\text { Canal wall up } \\
\text { mastoidectomy }\end{array}$ & 1 & 1.3 \\
\hline Total & 80 & 100 \\
\hline
\end{tabular}

Modified radical mastoidectomy with tympanoplasty was the preferred surgery in majority of cases (78) while attico-antrostomy and canal wall up mastoidectomy were done in a single case each.

Majority patients were operated under general anaesthesia (62 cases or $77.5 \%$ ). Since, ours is a teaching hospital, post aural approach was the preferred approach in most cases ( 78 cases or $97.5 \%$ ).

Table 4: Extent of disease involvement.

\begin{tabular}{|lll|} 
Extent of disease & No. of cases & $\begin{array}{l}\text { Percentage } \\
(\%)\end{array}$ \\
\hline Attic & 77 & 96.2 \\
\hline Additus & 72 & 90.0 \\
\hline Anrtum & 69 & 86.2 \\
\hline Sinodural angle & 51 & 63.7 \\
\hline Middle ear & 46 & 57.5 \\
\hline Facial recess & 31 & 38.7 \\
\hline Sinus tympani & 20 & 25.0 \\
\hline Facial canal & 22 & 27.5 \\
\hline $\begin{array}{l}\text { Lateral semi-circular } \\
\text { canal }\end{array}$ & 13 & 16.2
\end{tabular}

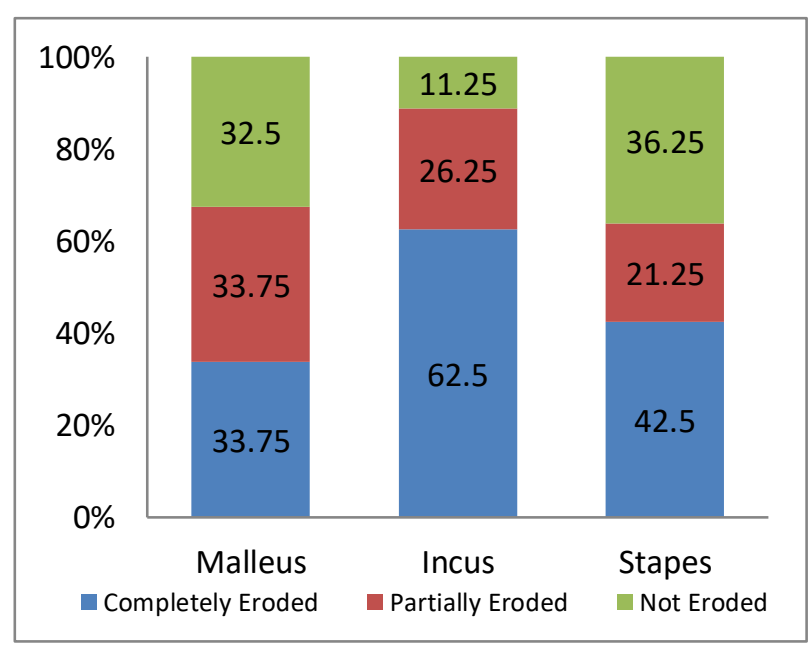

Figure 4: Ossicular status. 
Most commonly disease involved the attic, $96.2 \%$ cases, while the lateral semi-circular canal was involved in $16.2 \%$ cases respectively.

Intraoperatively, the ossicle most commonly affected by disease process was Incus (71 cases or $88.5 \%$ cases) while stapes was found to be most resistant to disease process ( 29 cases or $36.25 \%$ cases). In one case, all the ossicles were found to be malformed.

\section{DISCUSSION}

We studied a total of 80 patients with unsafe CSOM. We included patients of either sex up to 60 years of age. The study group comprised of 46 males and 34 females. Male: Female ratio was $1.35: 1$, thereby male preponderance was observed. Similar demographic profile with male preponderance was noted by Nagendran et al. ${ }^{1}$ There were 72 Hindu and 8 Muslim patients. The Hindu to Muslim ratio was 9:1. Majority of our patients (50 patients) were from rural area and the rest 30 from urban area. All patients in the study belonged to low socioeconomic strata. In previous studies, overcrowding, poor hygiene and living conditions have been implicated in the etiology of unsafe type of CSOM. ${ }^{2}$ Outdoor work and exposure to atmospheric and climate changes have previously been postulated as a cause in the development of $\mathrm{CSOM}^{3}$ Also, cholesteatoma has been found to be unrelated to hereditary factors; however, it is prevalent in patients from low socioeconomic strata where living conditions are poor and overcrowding is common..$^{4-7}$

Young adults in the age group i.e., 16-30-year age group $(47.5 \%)$ were the most predominantly affected section in this study group. Paediatric patients (Up to 15 years) constituted 23 cases (28.7\%) and disease was least common in the 46-60-year age group $(5 \%)$. In young adult's offensive ear discharge can lead to social isolation. They are usually self-dependent and therefore seek medical advice early. Similarly, the elderly is dependent on other family members to get them to a hospital for check-up, so their numbers are low. This explains the predominance of young adult males in our study group.

In our series, 35 patients had disease in left ear only, 31 in the right ear only and 14 patients had bilateral ear disease. 41 left and 39 right ears were chosen to be operated. Laterality of disease to any particular ear was not observed. Previous literature also does not suggest any particular ear to be more susceptible to atticoantral disease.

Symptomatically, 78 patients complained of foul smelling scanty purulent discharge (97.5\%), followed by hearing loss in 41 patients $(57.2 \%)$. Khan et al in their study had also documented ear discharge as the commonest symptom in unsafe CSOM in more than $90 \%$ cases which is similar tour study, followed by hearing loss in more than $82 \%$ cases. $^{4}$
16 had vertigo (20\%), 14 patients had otalgia (17.5\%), 8 had tinnitus (10\%), 4 each (5\%) had fever, headache, vomiting and seizures. Facial palsy was encountered in 2 cases $(2.5 \%)$ in our study which is comparable to up to $4.2 \%$ cases in a previous study by Khan et al. ${ }^{4} 1$ rare presentation in our series was a patient with trismus $(1.2 \%)$.

On otoscopic examination, tympanic membrane perforation was the most consistent finding. $67.5 \%$ cases or a total of 54 patients had perforation in the tympanic membrane. These included $38(47.5 \%)$ in the attic or pars flaccida, $12(15 \%)$ in the pars tensa, $2(2.5 \%)$ each of marginal and multiple perforations. Our patient with multiple perforations is the tympanic membrane had tubercular otitis media which is well documented as a cause for more than one perforation in the eardrum.

$15 \%$ of our patients had central perforations. They would have acquired the disease secondary to the perforation. Therefore, it is prudent to carefully examine the ears with central perforation and scanty, foul smelling, purulent ear discharge. Otoendoscopy will give a clear image of the middle ear through the perforation and features of atticoantral disease like, cholesteatoma or suspicious granulations can be picked up. Previous studies have reported pars tensa perforation ranging from 5-17\% cases and pars flaccida perforation in up to $82 \%$ cases of unsafe CSOM. ${ }^{4}$ Therefore a safe/central perforation does not rule out unsafe CSOM.

The next most consistent finding was frank cholesteatoma in 45 patients $(56.25 \%)$. In a previous study, $47 \%$ cases of cholesteatoma were also noted by Garap et al which is similar to our findings. ${ }^{11}$ Similar to this study, Asghar Ullah Khan et.al have reported cholesteatoma in $60 \%$ cases and non-cholesteatoma unsafe CSOM constituted $40 \%$ cases. $^{4}$ Anterosuperior and posterosuperior retraction pockets constitute $32.5 \%$ cases. Otherotoscopic findings include, posterior canal wall sagging $(16.25 \%)$, aural polyp $(10 \%)$, and sagging of roof of external auditory canal $(2.5 \%)$.

The patient group consisted of good number of patients from rural and poor socioeconomic background, where medical facilities are poor. Therefore, they mostly presented to us in a tertiary care hospital in late stages, with complications of unsafe CSOM.

Mastoiditis was the most commonly encountered complication preoperatively (27 cases). Mastoiditis has been seen to involve up to $7.4 \%$ cases in previous studies which is much lower than our study. ${ }^{4}$ Brain abscess and Labyrinthitis were less common constituting of 5 cases each. Lateral sinus thrombophlebitis was seen in 4 cases. Pre-operative facial palsy was a rare entity in this series with only 2 cases. Thus, both intra-temporal and extratemporal complications were encountered, but intratemporal complications constituted a greater fraction of our cases. The most unusual complication encountered in 
our series was trismus and retropharyngeal abscess in one patient.

On pure tone audiometry, conductive hearing loss was the commonest $(62 \%)$ type of hearing loss encountered. This was followed by Mixed hearing loss (23\%). Sensory neural hearing loss was rare $(11 \%) .3$ patients $(4 \%)$ had absolutely normal hearing.

According to previous literature, conductive hearing loss is attributed to ossicular erosion involvement by disease process while toxic products of inflammation, drug toxicity can result in sensorineural hearing loss. ${ }^{4,8-10}$

On X-ray mastoid Schuller's view, all the 80 mastoids showed sclerosis. Secondary sclerosis (57.8\%) was commoner than primary sclerosis $(42.2 \%)$ in this study group. Erosion with secondary sclerosis was present in only 3 cases. Thus, sclerosis on X-ray mastoid can be concluded as a definitive feature of unsafe CSOM. Contrary to our findings, pneumatised mastoids have been seen in up to $28.94 \%$ cases of unsafe CSOM in other studies, whereas we found all the mastoids to be sclerosed in this series. High resolution computed tomography scan of the mastoid was reserved for patients presenting with complications of unsafe CSOM.

The disease was seen most consistently involving the attic $(96.2 \%)$, additus $(90 \%)$ and antrum $(86.2 \%)$. Other commonly involved sites were the sinodural angle $(63.7 \%)$, middle ear (57.5\% cases). Differing from our study, previous studies have documented involvement of both attic and antrum (60\%) more common than antrum $(20 \%)$ and attic (10\%) separately. ${ }^{11}$

The facial canal was involved in 22 cases $(27.5 \%)$. Among those, the horizontal segment was most frequently involved ( 7 cases) followed by the vertical segment and $2^{\text {nd }}$ genu (5 cases). Both, horizontal and vertical portion, and horizontal portion and $2^{\text {nd }}$ genu was affected in 2 cases each while vertical portion and $2^{\text {nd }}$ genu was involved in 1 case. However previous studies have documented up to $60 \%$ facial canal dehiscence probably because of advanced disease. ${ }^{11}$

Similarly semi-circular canal involvement was seen in a total of 13 cases (16.2\%). 12 involved the lateral semicircular canal (7 erosion and 5 fistulas). Posterior semicircular erosion was seen in 1 case. Previous studies in the 1990s have reported incidence of semi-circular canal involvement in up to $60 \%$ cases. ${ }^{11,12}$ This shows that with timely diagnosis, disease can be picked up in early stages and complications can be prevented.

Among the ossicles, incus (71 cases) was the most susceptible one. Malleus was affected in (54). Stapes was found to be most resistant to disease process (51 cases). Among the, all ossicles were found to be malformed in 1 case.
Co-relating with our study results, Varshney et al' also found the Incus to be most commonly eroded. It was intact in only $15 \%$ cases, necrosed in $45 \%$ and absent in $40 \%$ cases. The lenticular process $(40 \%)$ and the long process $(38.3 \%)$ were mainly affected. Malleus was intact in $55 \%$ cases, necrosed in $35 \%$ and absent in $10 \%$ cases. Stapes was eroded in $48.8 \%$ and intact in $51.67 \%$ cases. Only $15 \%$ cases of unsafe CSOM showed an intact ossicular chain. ${ }^{3}$

Kartush and Garap et al had found also the incus to be the most commonly affected ossicle, while Sade et al had found the malleus necrosis in $26 \%$ cases. ${ }^{2,10-12}$

These patients after mastoid exploration were kept admitted in the ward for a week. Intravenous antibiotics were given and regular dressings were done. Suture removal was done on the $7^{\text {th }}$ post-operative day. None of the patients revisited us with residual disease or had to undergo a revision surgery in the next 1 year.

\section{CONCLUSION}

Late presentation of unsafe CSOM is common in patients belonging to rural areas where healthcare facilities are poor. Therefore, prompt and systematic approach of patients presenting with ear discharge is necessary. A central perforation does not rule out unsafe CSOM. Pus culture and sensitivity is a useful tool to improve the surgical outcome and achieve a dry ear. CT scan should preferably be done in suspected complication cases to exactly localise the disease and its related complications. Since hearing loss is a common symptom and ossicular necrosis, especially of incus was most commonly encountered, mastoidectomy with tympanoplasty is necessary for hearing rehabilitation either in the same sitting or as a second stage surgery. Also, to obtain a dry ear, canal wall down mastoidectomy is a good single stage surgical option non-compliant patient.

Funding: No funding sources

Conflict of interest: None declared

Ethical approval: The study was approved by the Institutional Ethics Committee

\section{REFERENCES}

1. Navaneethan $\mathrm{N}$, YaadhavaKrishnan RD, Muthukumar U, Harihara R. Our experience of unsafe ear. Indian J Otol. 2015;21:37-40.

2. Sade J, Berco E, Buyanover D, Brown M. Ossicular damage in chronic middle ear inflammation. Acta Otolaryngol. 1981;92:273-83.

3. Varshney S, Nangia A, Bist SS, Singh RK, Gupta N, Bhagat S. Ossicular Chain Status in Chronic Suppurative Otitis Media in Adults Indian J Otolaryngol Head Neck Surg. 2010;62(4):421-6.

4. Khan MF, Khan AU, Iqbal J, Amjad M. Ossicular changes in choroni9c suppurative otitis media. 
Atticoantral Dise Ann KE Med Coll. 2006;12(3);396.

5. Aberg B, Westin T, Tjellstrom A, Edstrom S. Clinical characteristics of cholesteatoma; Am J Otoloryngol. 2013;12:254-8.

6. Vartiainen E. Changes in the clinical presentation of chronic otitis media from the 1970 s to the 1990s. J Laryngol Otol. 1998;112:1034-137.

7. Khemani A, Akhund AA, Shakh AB. Bacteriology and its effects on clinical presentation and treatment results of chronic suppurative otitis media (CSOM). Med Channel 1999; 5(1):35-8.

8. Martins O, Victor J, Selesnick S. The relationship between individual ossicular status and conductive hearing loss in cholesteatoma. Otol Neurotol 2012;33(3):387-92.

9. Pal $\mathrm{MB}$, Khan $\mathrm{N}$; Incidence of complications in temporal bone due to cholesteatoma. Pak Postgrad Med J. 1995;10(4):109-11.
10. Kartush JM. Ossicular chain reconstruction. Capitulum to malleus. Otolaryngol Clin North Am. 1995;27:689-715.

11. Garap JP, Siba P. Dubey Canal-Down Mastoidectomy: Experience in 81 Cases. Otol Neurotol. 2001;22:451-6.

12. Kurien M, Job A, Mathew J. Otogenic intracranial abscess: concurrent craniotomy and mastoidectomy: changing trends in a developing country. Arch Otolaryngol Head Neck Surg. 1998;124:1353-64.

Cite this article as: Hansdah R, Sachdeva K. Spectrum of clinical characteristics of chronic suppurative otitis media unsafe type: a retrospective study from a tertiary care teaching hospital in Central India. Int J Otorhinolaryngol Head Neck Surg 2021;7:1105-10. 